\title{
Unbearable Lessons: Contesting Fat Phobia in Physical Education
}

\author{
Heather Sykes \\ University of Toronto \\ Deborah McPhail \\ York University
}

In this article we examine how fat-phobic discourses in physical education both constitute, and are continually negotiated by, "fat" and "overweight" students. This claim is based on qualitative interviews about memories of physical education with 15 adults in Canada and the U.S. who identified as fat or overweight at some time during their lives. The research draws from feminist poststructuralism, queer theory, and feminist fat theory to examine how students negotiate fat subjectivities in fat-phobic educational contexts. The interviews reveal how fat phobia in physical education is oppressive and makes it extremely difficult for most students to develop positive fat subjectivities in physical education; how weighing and measuring practices work to humiliate and discipline fat bodies; and how fat phobia reinforces normalizing constructions of sex and gender. The interviews also illustrate how some students resisted fat phobia in physical education by avoiding, and sometimes excelling in, particular physical activities. Finally, interviewees talk about the importance of having access to fat-positive fitness spaces as adults and suggest ways to improve the teaching of physical education.

Dans cet article, nous examinons comment, en éducation physique, les discours adipo-phobiques construisent discursivement les étudiants corpulents et sont continuellement négociés par eux. Cette affirmation est fondée sur des entrevues avec 15 adultes canadiens ou américains qui s'identifient comme « gros » ou ayant du « surpoids » à un moment dans leur vie et à qui on a demandé de discuter de leurs souvenirs de l'éducation physique. Cette étude emprunte aux théories poststructuraliste, « queer » et féministe pour examiner comment les étudiants négocient leurs subjectivités en tant que "gros » dans un contexte éducatif adipo-phobique. Les entrevues révèlent que : la peur du gras corporel en éducation physique est oppressive et rend difficile le développement de subjectivités corpulentes en éducation physique ; les pratiques de mesure du gras et du poids humilient et disciplinent

Heather Sykes is with Curriculum, Teaching, \& Learning, OISE/UT, University of Toronto, 252 Bloor Street West Toronto, Ontario, Canada. Deborah McPhail is with the Women's Studies Department, York University, Toronto, Ontario, Canada. 
les corps plus gros; et l'adipo-phobie renforce les constructions normalisatrices du sexe/genre. Les entrevues illustrent comment les étudiants résistent à l'adipophobie en éducation physique en évitant des activités physiques particulières. Enfin, les participants parlent de l'importance de l'accès à des espaces d'activité physique qui soient positifs pour les adultes corpulents et suggèrent des façons d'améliorer l'enseignement de l'éducation physique.

\section{Q: What do you think they were trying to teach you [in physical education]?}

Karen: I think it was to just let the kids have healthier bodies, and that would in turn increase their abilities in the classroom. But I don't necessarily think that's what really happened or what the hidden agenda was.

\section{Q: What do you think the hidden agenda was?}

Karen: I think even back then there was definitely this fat-phobic attitude. I think that a large part of it was just trying to eradicate the fatness of the kids. 'Cause I was in elementary school in the late 70s and early 80s, and I think that was probably around the time where it was really being noticed that the kids were being more sedentary. I think that phys ed was used to combat that.

In this article we examine different aspects of what Karen referred to as "this fat-phobic attitude" in physical education. We argue that fat-phobic discourses in physical education both constitute, and are continually negotiated by, "fat" and "overweight" students. Our observations are based on interviews with 15 people, as part of a larger research project, who self-identified as fat or overweight about their experiences in physical education. This project involved adults looking back on their schooling experiences to find out how people's fat subjectivities were negotiated during school and subsequently changed after leaving school. Their recollections of physical education were overwhelmingly negative, ranging from horrific and traumatic to incredulous and cynical. These memories of physical education illustrate how fat-phobic discourses construct the fat body as out of control, out of place, and out of shape. Many people recalled feelings of alienation, dread, and disembodiment that indicate how the possibility of fat subjectivity was repeatedly foreclosed during physical education. Moreover, because fatness is conflated with excess femininity, fat phobia also reinforces normative constructions of gender and sex that compounds the problem for sexual and gender minority students. People's experiences of being publicly weighed exemplify how fat phobia strives to discipline the "unhealthy" fat body. Nevertheless, at times, some individuals described how they managed to contest the healthiest discourse that fat is unhealthy and unfit by refusing, avoiding, and sometimes excelling in physical education. In team-game situations, many fat people frequently recalled feeling humiliated, vulnerable, or incompetent, although some negotiated the pervasive fat phobia in baseball and field hockey by reimagining fatness in terms of strength or speed. As adults, a small number of women actively contested fat phobia by seeking out or asserting fat-friendly politics and policies in their fitness classes and clubs.

The interviews reveal how fat and overweight students were able to form fluid identifications as fat, athletic, and healthy even within hostile educational climates. Generally speaking, however, fat people's memories of physical education at school 
illustrate how fat phobia created extremely difficult situations that demanded constant psychic/emotional work, provided pitiful opportunities for learning, and numerous alienating and traumatic movement experiences. Thus, just as Susan Bordo (1993) argued that being fat in contemporary culture is an unbearable weight for women, we suggest that being fat makes physical education an unbearable lesson for many students.

\section{Methodology}

This article is based on interviews conducted as part of a larger project examining heterosexism, transphobia, ableism, and body-based discrimination in Canadian physical education. Participants in the project were required to self-identify with one or more of the following marginalized social groups: sexual or gender minority; having a physical disability; or having an undervalued body size/shape. This article is based on 15 interviews with people who self-identified as "fat" or "overweight" from a total of 35 interviews conducted for the overall project. On a demographics form, participants described their identities in the following areas: sexuality, gender/sex, racial/ethnic, class, physical disability, other disability, and body shape/size.

Participants who identified as fat or overweight had diverse gender/sex identities (female, male, butch, intersex) and sexual identities (straight, gay male, bi, lesbian, queer). This article provides a limited analysis of racialized experiences of fat subjectivity because all people who self-identified as fat or overweight also identified primarily as White, although participants in the larger project described their racial/ethnic identities as Asian, Black, Native American, Hispanic (6); Jewish (5); Canadian, Western European, Eastern European (3); White, WASP, Caucasian (21). We chose to interview adults because they could provide information about changes in fat subjectivities over their life spans, which allowed us to learn from their retrospective sense-making about their experiences at school.

Members of the research team used their personal contacts to find participants; this was followed by a limited snowball technique. Each member of the research team had personal, activist, or professional involvement in one or more of the marginalized groups that provided crucial access to these populations. Most people interviewed were located in the greater Toronto area, although a small number of participants were based in other Canadian and U.S. locations. The research team conducted one pilot focus group (Fern, 1982) followed by 35 semistructured, individual interviews that were audiotaped and transcribed verbatim using a protocol developed by Mishler (1991, 1995). Researchers approached the semistructured interviews as intersubjective conversations (Kvale, 1995) in which all interviewers asked questions based on a common interview guide; in addition, they asked extension questions based on their own perspectives and relationships with interviewees. Interview topics included individual's memories of physical education; confidence in physical abilities and feelings about their body; the impact of physical education teachers; and what physical educators might learn from the participant's experiences of marginalization. Participants were requested to choose their own pseudonym, and researchers subsequently inserted pseudonyms for the real names of all other people and places. Interviewees were invited to verify and edit their own interview transcript. 
For this article, the coauthors initially read the transcripts to identify material related to the interview questions (memories of physical education; confidence in physical abilities and feelings about their body; impact of physical education teachers; what physical educators might learn from the participant's experiences of marginalization). We independently inserted comments beside select interview excerpts according to interview themes and specific themes within feminist fat theory. Secondarily, the authors collaboratively selected and interpreted these excerpts using Kvale's (1995) condensation and interpretation approaches to qualitative interview analysis.

\section{Literature Review}

\section{Critical Analyses of Fatness in Physical Education}

The discourse of "healthism," first suggested by Robert Crawford (1980), assumes that individuals can achieve health through individual effort and discipline, mainly by regulating the size and shape of the body (Colquhoun, 1990; Kirk \& Colquhoun, 1989). Kirk and Colquhoun documented how this individualistic view of health, linked to the assumption that "exercise = fitness = health" (p. 426), underpinned the push for health-based physical education approaches and daily physical education programs in Australian schools in the 1980s. At a school level, they reported that many teachers conducted daily fitness sessions, not for educational reasons, but because of concerns about students' physical health that were articulated in terms of students' body weight and size:

I think there's a definite need for it [daily physical education] here. . . . You just have to look around and you can see the guts developing already at this stage. (Female generalist teacher; Kirk \& Colquhon, p. 425)

There's a lot of fat children around, obese is a nice word for it I suppose. . . . There are overweight kids here, you see them at swimming and you can't even see the top of their togs! (Male generalist teacher; Kirk \& Colquhon, p. 425).

Thus, almost 20 years ago, Kirk and Colquhoun asserted that " the implicit belief among many physical educators is that . . . being fit and having a slender body are proof of health" (p. 426) and that "fatness is the dominant concern of healthoriented physical education (p. 430). A few years earlier, Richard Tinning (1985) had urged physical educators to teach students how to critically address the "cult of slenderness" that valorizes the "slim, trim, firm and taut" body.

These analyses are still highly relevant today according to John Evans, Bethan Evans, and Emma Rich (2003), who suggest that a "culture of weightism" persists in physical education despite ongoing critical scrutiny of this issue since the early 1980s. Indeed, both Tinning and Kirk (2006) have recently returned to the issue with updated analyses of the contemporary obesity discourse. The "cult of slenderness" has now developed into the "cult of the body," suggest Tinning and Glasby (2002), with earlier concerns about a "CHD (cardiovascular health disease) epidemic" being replaced by the current moral panic about an "obesity epidemic." The most significant analysis of the current obesity epidemic by physical education scholars is undoubtedly the work of Michael Gard and Jan Wright (2001, 
2005) who meticulously document how uncertainty about obesity research within the biomedical field is replaced with certainty in the "expert" knowledge about obesity within physical education. They go on to articulate three implications of this recontextualization of obesity science for physical education:

1. physical education legitimates itself on the basis of unwarranted and ethically unresponsible claims about obesity and overweight;

2. effects of the obesity discourse on students and the public are detrimental rather than productive with respect to health;

3. physical education, as a profession, is served by uncritically accepting the obesity discourse because it generates resources and recognition.

These critical analyses have informed a number of empirical studies in the U.K., U.S., and Australia into the impact of discourses about healthism, obesity, and slenderness on the subjectivities of students (Burns, 1998; Norman, 2005; Rich, 2003) and teachers (Morimoto, 2006) in physical education. Our study contributes to ongoing critical research that is documenting the detrimental effects of the obesity discourse on students in physical education.

\section{Theoretical Framework of Fat Subjectivity and Fat Phobia}

Poststructural feminism, queer theory, and feminist fat theory inform our theoretical framework for examining how students are constituted by and at the same time contest fat-phobic discourses in physical education. Specifically, our analysis uses the following conceptualizations of fat subjectivity and fat phobia.

\section{Fat Subjectivity}

Fat subjectivity refers to the incorporation of fat subject position(s) into a person's overall embodied subjectivity. Embodied subjectivity is a poststructural conceptualization of the self that refers to the intersections between the body, the social, and the psyche. Students' embodied subjectivities are constructed within a normative gender-sex system (Benhabib, 1992: Prosser, 1998) that is racialized (Ahmed, 2004; Shaw, 2005) and overvalues productive, thin bodies (Bordo, 1993; Herndon, 2002; McRuer, 2006). The construct of embodied subjectivity is an area of current interest within sociology (International Sociological Association, 2002) and physical education (Macdonald, et.al., 2002). Kathleen Armour (1999) recently called for a body-focused rationale that acknowledges that the social impinges upon students' embodiment and that physical education is central to the development of students' embodied identity. Our theoretical framework differs slightly from Armour's conceptualization of self-identity because we also consider psychic aspects of embodiment stemming from corporeal feminism (Diprose, 2002; Gatens, 1996; Grosz, 1994, 1995; Weiss, 1999), queer theory (Butler, 1997; Moon \& Sedgwick, 2001; Sullivan, 2003), critical disability theory (Schildrick, 2002) and psychoanalytic theory (Anzieu, 1989; Schilder, 1978).

The notion of fatness as a stable identity has evolved into fatness as a somewhat fluid subject position within a person's multifaceted embodied subjectivity. Older 
feminist literature on fat experiences, such as Schoenfielder and Wieser's (1983) Shadow on a Tightrope, regarded the "fat kid" experience as given; assuming that fat kids were hyperaware of their fat, and that they are always and ubiquitously fat. Later literature, such as Braziel and LeBesco's (2001) Bodies Out of Bounds, regards fat as more fluid and the identity category as contingent upon other discursive interpolations of identities. By way of illustration, this comment from Elizabeth, one of the paricipants, reflects the shifting and often belated nature of forming an identity as fat:

Elizabeth: Often I went through phases where-and this is in Judith Moore's Fat Girl book where she said, "I didn't realise I was fat until I was in situations where it was pointed out to me." And so often when I was growing up, I really did like myself, I was pretty proud, I had a pretty good level of self-esteem.

April Herndon (2002) explains how recognizing that fatness (and disability) are fluid subject positions; she moves away from ideas of "inherently flawed bodies" (p. 132) toward accounts of "dynamically situated bodies and identities" (p. 132). This means that:

our bodies are forever in the process of undeclared construction, and once we dislodge fatness from biology and begin to start thinking of who is categorized as fat as a social decision (in the same way that categorizing who is disabled is a social decision) what once appeared as solid categories surface as fluid boundaries. (p. 132)

Similarly, Sara Ahmed (2004) explained how fat bodies are read in terms of identities, such as Aboriginality, women, and class, which are constantly negotiated in everyday encounters. During the interviews it became clear that the identity category of fat is fluid not only within a person's individual life history but also in relation to different physical education spaces and the actual movements of the body.

\section{Fat Phobia}

Fat phobia in physical education stems, in part, from discursive processes that seek to maintain a precarious boundary between being fat and not being fat. In individualistic terms, people who are not fat fear becoming fat, or have a fat-phobia (Longhurst, 2005), so that "when I look into the mirror I see a thin/skinny person, but as soon as I walk away I imagine myself as fat" (Cooke, 1996, p. 202). In the cultural imagination, fears about be/coming fat arise from underlying anxieties about female reproduction, miscegenation, and pollution of bodily boundaries (Bordo, 1993; Gilman, 2006; Kristeva 1982). Fat-phobic underpinnings of the obesity epidemic involve the abjection ${ }^{1}$ of supposedly unhealthy, unathletic, and unskilled bodies from the imagined spaces of physical education and health education. Evans, Evans, and Rich (2003) describe the contemporary biomedical discourse of the obesity epidemic as a "cultural toxin: a powerful influence, not just upon public policy and practice in health-promoting agencies, but also on the public psyche and the mindset of teachers in schools" (p. 224). Thus, healthy living comes to require the elimination of fatness from the psychic, social, and national body. 
Obesity discourse generally conflates being fat with being unhealthy. The logic underpinning this obesity discourse relies on seemingly indisputable, if not causal, relations between medicalized notions of fatness, body weight, physical activity, diet, and health. Feminist scholarship (cf. Rice, 2006, 2007; Schoenfielder \& Wieser, 1983), however, along with Gard and Wright's (2005) feminist-influenced contribution to health and exercise studies, The Obesity Epidemic, question this medicalized solipsism between fat and unhealth by uprooting its scientific groundings. Arguing that "many aspects of both the causes and consequences of overweight and obesity ... are poorly understood" (p. 37), Gard and Wright (2005) maintain that the major problem with obesity science is its reliance on the notion that the body functions like a machine. The predictable, immutable, and metabolic body of obesity science becomes fat in one primary way; when calories consumed by eating (energy-in) exceed one's calories burned through exercise (energy-out). This energy-in/energy-out equation is commonsense, Gard and Wright argue, even in the face of scientific evidence to the contrary that disputes obvious correlations between increased exercise and increased weight loss, and between low exercise levels and high body fat. Scientific evidence also exists that questions an easy causality between overeating and fatness and between fatness and any environmental factor.

Like Gard and Wright, feminist scholarship questions science-based conflations between body fat, fat bodies, and being unhealthy. Carla Rice (2006) argues that dieting, a practice in which most fat people engage, might be less healthy than, and indeed cause, the so-called "effects of obesity":

Not only are diets ineffective in the long-run, but it is now clear that they have their own set of hazards. In addition to inadequate nutrition, dieting has been implicated in the development of weakness, fatigue, binging, bulimia, weight gain, obesity, and sudden death from damage to the heart. . . . Dieting may also be associated with diabetes and heart disease. (p. 414)

Along similar lines, feminist writers like Norman (1983), Hubbard (1983), Lyons (1989), Freespirit and Alderbaran (1983), and Mayer (1983), writing about fat in the 1980s, argue that fat in-and-of-itself is not unhealthy, but fat phobia is. Mirroring our participants, such feminist writers relate experiences of fat phobia that are both psychically and physically unhealthy. As Mayer (1983) states, "health problems of fat people are not inherently due to fat, but are the result of stress, self-hatred, and chronic dieting" (p. xii). Many of the people we interviewed also articulated this disjuncture between un/health and fat created by fat phobia. Both our participants and feminist literature suggest, then, that mechanistic medical and scientific paradigms equating fat with lack of health, such as the paradigm of energy-in/energy-out, are inadequate if not fat phobic.

For feminists, their undoing of the science of fat leads them to beg the question: If fat is, in fact, not unhealthy, why is medical science so concerned with proving that it is? To this end feminists argue that fat is pathologized because fat is symbolically conflated with women. As Rice (2006) argues, the "war on fat" is a "war on women." This war is waged, feminists argue, under the symbolic banner of Cartesian dualism. Bordo (1993), Grosz (1995) and Butler (1992) each show that the body becomes conflated with women through Cartesian dualism, or the mind-body split. Women are defined as "the body," and their reproductive 
capabilities are cited as the reason for this definition (Malson, 1998). Theorists argue that fat people in general, and fat women in particular, are positioned as the body in Cartesian dualism because of their excess corporeality. Symbolically speaking, fat people are excessively body, all body. Fat people's supercorporeality associates them with women, who are already codified as body, and, because fat people are too much body, they are "too much woman." This phenomenon in which fat people are "too much woman" has particularly gendered inflections, because fat women are positioned as "hyper-women" in patriarchy ${ }^{2}$ whereas fat men are emasculated-they are "failed men" (Mosher, 2001).

Moreover, these representations are racialized in ways that shore up unnamed, yet idealized, Whiteness. Not only does Cartesian dualism overdetermine women as "the body" but also people of color and racialized people (Bordo, 1993). Such a conflation is the result of racist and long-held understandings of people of color and racialized people as closer to nature and animalistic (Hill Collins, 1997). In Cartesian logic, then, not only is fat feminine, but it is also racialized. For example, Shaw (2005) traces how iconic representations of the Black female body in the United States overwhelmingly define the standards against which White femininity is constructed. Fatness and Blackness, she argues "display an uncanny coincidence of boundaries" (Shaw, 2005: 152) such that the Black female fat body signals a concentration of asexualized, maternal plenitude. ${ }^{3}$ Recently, this feminist scholarship has been taken up in relation to the fat male body by Moss Norman (2005), who, in his study of male youth in Ontario high schools, argues that obesity discourse is an important boundary project in the production of clean and proper White masculine subjects.

\section{Fat Phobias Are Historically and Spatially Contingent}

When discussing fat phobia, it is important to recognize that cultural attitudes about fatness are historically and spatially contingent. Current mainstream discussions about fatness are generally ahistorical. In government policy and articles in the popular press (cf. Argell, 2005; Evenson, 2002a, 2002b, 2002c; Health Canada, 2002; Kennedy, 2005; Kirkey, 2002; Moore, 2005; Ogilvie, 2006), a palpable and sensational belief about the newly growing numbers of fat people grounds antifat discourses and discursive practices. Historical accounts of fat decrease the sensational sense of novelty accompanying current discussions about fat and prompt a more careful analysis of both the numbers and the epistemologies of fat.

Four important historical works that contextualize fat in history are Stearns' (2002) Fat History, Schwartz's (1986) Never Satisfied, Huff's (2001) A “Horror of Corpulence," and Gilman's (2004) Fat Boys. Implicating such social structures as race, gender, nation, and economy in fat phobia, Stearns, Schwartz, Huff, and Gilman focus on the meanings of fat in the West, pointing to the fluidity of both the scientific and cultural understandings of fat. Definitions of fat, each argues, have historically fluctuated in tandem with cultural shifts in both economy and in gender relations. For instance, Stearns' (2002) American focused work, which argues that "concern about weight and dieting is not timeless" (p. xx), maps the late-nineteenth- and early-twentieth-century shifts in epistemologies of fat, relating them to concomitant upheavals in gender relations. Emerging from the Victorian age, Stearns argues, American women were engaged in the public sphere as never before, because women's participation in the paid workforce and in the political 
arena became increasingly pronounced. As such, Victorian distinctions between women and men, which had teleologically informed and relied upon the cleavages between the public and the private spheres, were less valid. To contain, or at least assuage, the gender panic that accompanied this delegitimation of Victorian gender classifications, impossibly high standards of thinness for women emerged. These standards hinged themselves to a previously developed strain of fat phobia that arose from Americans' collective guilt about capitalist expansion. Stearns argues:

With dieting established as a moral category, available to compensate for real or imagined indulgence in other facets of American society, it could be ratcheted up to attach to additional moral issues posed by particular segments of the population. . . . The result was a frenzy of diet materials explicitly directed at women ... as overt attention to weight became a new gender divide in a period when gender distinctions of other sorts were diminishing (pp. 71-72).

If women and men could no longer be as confidently distinguished by the private-public binary, then at least their bodies, and the practices that disciplined them, were different.

Historical writers also situate epistemologies and the quantification of fat in discourses of race and processes of racialization. Gilman (2006), for example, argues that the contemporary moral panic about obesity is part of a discourse on race that surfaced in the nineteenth century, producing anti-Semitic categories of Jewish "racial adiposity," that continues to shape racialized medical understandings of obesity (Gilman, 2006). He traces the centrality of the male Jewish body in early twentieth century correlations between diabetes and obesity, which, since the 1960s, shifted scientific interest onto the "thrifty genotype" located within immigrant and indigenous bodies. Gilman also situates Hilde Bruch's psychoanalytic ideas about anorexia and obesity within a historical context, detailing how Bruch rebelled against her medical training in 1920s Germany that asserted that Jews, as a "race," were predisposed to diabetes and obesity. After escaping Nazi Germany and emigrating to the United States, Bruch offered an alternative psychoanalytic model ${ }^{4}$ of obesity that went against the dominant racial model of obesity in Germany and also against the metabolic model that was prevalent in the US during the 1930s and 40s. Gilman explains how Bruch's clinical work on the psychosomatic aspects of body size gave rise to her theory of "developmental obesity" (p.63), which linked an individual's developmental changes with the external dynamics of the pathological family, notably the mother. In Bruch's view, obesity developed as a result of family interactions during childhood, particularly the child's struggle to develop autonomy. Her psychoanalytic perspective of obesity contrasted with the racial and biological theories of obesity that dominated medical discourse and, though problematic in contemporary terms, emerged as a "non-racial, non-biological answer to what had been a racial and/or biological explanation" (p.64).

Historically specific understandings of fatness were articulated to different degrees in participants' narratives about their embodiment. We became ethnographic witnesses (Jacobs, 2004) to the Holocaust in one particular interview with Moe, whose testimony profoundly implicates our analysis about fat phobia in physical education within a difficult conversation in the "(post) holocaust era" (Morris \& Weaver, 2002). Moe linked his fatness to his mother's continual feeding, which he understood in relation to her memories of famine during the Holocaust. 
Moe: I got tall, quite tall, when I was 11 or 12, and I started gaining weight until I could be considered overweight in high school, and it got worse as an adult. I'm pretty big right now.

Q: I'm not sure if you want to share a little bit, because I know the background about the concern about your weight, about the background of being born in a displaced persons camp in Europe?

Moe: Yes. I was born in Germany in a displaced persons camp, a sort of a holding camp. My parents were waiting to be placed somewhere else, and they got accepted into Canada and came to Canada with me in ' 48 . I was about 18 months old. My father worked hard. My mother stayed at home. I think the fact that she went hungry during the war . . food became a very important thing. She just cooked and baked constantly. So maybe that was some of my problem. I think I developed into a pretty big eater.

The figure of the overfeeding M/other in Moe's narrative is historically contingent on memories of famine during the Holocaust across generations of the North American Jewish diaspora. Thus, histories of fat allow us to contextualize past and, by important extension, current understandings of fat in social structures like gender, diasporas, and economies. Along with contextualization, histories also urge us to be specific about fatness and fat phobia-to always qualify any discussion of fat with a definitive nod to its historical fluidity.

A spatializing of fat prompts a similar kind of contextualization and specification but focuses on the coproduction of fat phobia and the spaces in which it is experienced. Considering fat phobia at the level of the nation-state, for example, implicates gendered and racialized nation-building practices in the regulation of fat bodies. Carla Rice (2007) has analyzed how national imaginings of the fit and slender body helped to produce Canadian girls' experiences of fat phobia in the 1970s and 1980s. Such state-instigated programs as Participaction and the Canada Fitness Test, designed to encourage Canadians to lose weight and increase fitness levels, facilitated both self-debasement and destructive eating and exercise practices in the "fat girls" interviewed by Rice. Following the example of current national policies such as the so-called Romanow report (Health Canada, 2002), the Ontario Ministry of Education introduced a policy of "daily physical activity" in 2005 that mandated all elementary students have a minimum of 20 minutes of sustained moderate-to-vigorous physical activity per day. This policy was justified in terms of a new obesity panic because, according to the provincial government, "during the past twenty-five years, obesity rates among Canadian children have increased substantially" (Ontario Ministry of Education, 2005). More recently, in 2007, the Government of Canada introduced a $\$ 500$ tax credit for parents who register children in physical activity programs that "can be reasonably expected to result in improved fitness" (Parks and Recreation Ontario, 2007). In the U.K. cities are now being ranked on a "Fat League Table" that is part of an emerging political economy of fat (Brabazon, 2006; Marvin \& Medd, 2004).

Thus, as numerous feminist geographers argue (cf. Callard, 1998; Duncan, 1996; Johnston, 1998; Longhurst, 2001; Moss \& Dyck, 2002), discourses attached to a particular space, in these instances the Canadian nation-state, not only produce particular beliefs and attitudes about bodies but conterminously produce the actual 
physicality of bodies (Colls, 2007). Fat embodiment therefore-the process of becoming a fat body - is a spatially situated, psychic event founded in fat-phobic discourses about "good" and "bad," "healthy" and "unhealthy" bodies.

Recent feminist scholarship, particularly postmodern and psychoanalytic work regarding subjectivity and subject formation, has emphasized the concept of agency and small-scale resistances. Embracing the understanding that experiences of self are discursively produced (Scott, 1992), postmodern and psychoanalytic feminists argue that, as an interface of sometimes-competing, sometimes-complimentary, and always-negotiated unconscious processes, subjugated consciousnesses are never complete or intact (Butler, 1993, 1997; Fuss, 1995; Fraser \& Nicholson, 1990; Mouffe, 1997; Weedon, 1997). As such, subjects can at once consume and resist dominating discourses, often in subtle, individual ways. Although a subject may, in fact, be encouraged to take up a particular sexed, classed, raced or, in the context of physical education, a healthist discourse, neither means that the discourse is incorporated nor incorporated "correctly" by the subject. Such an understanding of subject formation is encouraging to feminists such as Judith Butler (1993, 1997), who understands these instances of inevitable mis-incorporations not only as moments of agency but also as moments of resistance.

In The Psychic Life of Power, Butler (1997) argues that unconscious processes of discourse negotiation create the potential for radical change to dominant discourses and the power relations that produce them: "The act of appropriation may involve an alteration of power such that the power assumed or appropriated works against the power that made that assumption possible" (p. 13). Postmodern and psychoanalytic attentions to agency are imperative when analyzing the experiences of our research participants in physical education. Our analysis of the interviews is thus two-pronged, because we celebrate the agency of participants and fight against the social structures that make the resistance both possible and necessary in the first place.

\section{Themes}

The five themes in the next section start by illustrating how fat-phobic discourses made physical education extremely difficult for many students and then move toward documenting how students negotiated and resisted these discourses. Three themes portray how the formation of a livable fat subjectivity was so often impossible, or foreclosed, in physical education, producing feelings of dread, alienation, and disembodiment in students; how techniques of weighing and measuring operate to discipline the fat body in physical education; and how female, gay, queer, and intersex students negotiated normalizing constructions of sex and gender within fat-phobic discourses. The last two themes document how students contested fat phobia by avoiding, and sometimes excelling in, specific physical activities, and how two participants, as adults with access to fat activism, now have positive experiences in aerobics and fitness gyms despite their negative experiences in school physical education.

\section{Theme Number 1: The Foreclosure of Fat Subjectivity}

Several Canadian studies have examined how students are affected by obesity discourses and the trend toward "fat-free schooling" (Evans et al., 2002). Canadian 
female youth are generally less physically active than male youth, as well as more concerned about being overweight (Wharf Higgins, Gaul, Gibbons \& Van Gyn, 2003). In Southern Ontario, a recent study of 2,279 girls reported almost one-third of girls who are of healthy weight are currently dieting because they believe they are too fat (Jones, Bennett, Olmsted, Lawson \& Rodin, 2001). In Toronto schools, body-based discrimination based on physical appearance and size is a regular occurrence (Rice \& Russell, 2002). Physical and health education play a central role in contributing to these weight concerns and dieting practices of Canadian youth by constructing fatness in negative and, sometimes, pejorative terms. This first theme illustrates how physical education practices foreclosed the possibility for students to form enabling, positive identifications with fatness while they were in school.

Many people we interviewed highlighted the continuous psychic work required to inhabit fatness as an "emotional size" (Colls, 2002: 219) in physical education. Most women, and some men, that we interviewed consistently reported how their experiences in relation to body size and fatness in physical education produced feelings of alienation, dread, and, at times, disembodiment.

We start by sharing narratives from three women, Temperance, Starburst, and Elizabeth, that are representative of participants' overall negative memories of physical education. These three women all identified their racial/ethnic identity as WASP (White, Anglo-Saxon, protestant) but had various sexual and gender identities: Starburst self-identified as a queer woman; Temperance described her sexuality as queer and her gender as biofemme ${ }^{5}$; and Elizabeth self-identified as a straight woman. ${ }^{6}$

Temperance: My experience of phys ed and school went hand-in-hand with trauma I had at home around weight loss and trauma I had at school around fat phobia. It was all part of one package and alienated me from my body.

Q: What do you think you learned from physical education?

Starburst: How to avoid it. [Both laughing]. I think that I learned that I didn't like anything that had to do with moving. . . . And I like solitary activities. I like to swim by myself. I like to go to the gym where I'm by myself. There's this kind of cone of individual. I don't like team sports at all. I really dislike them a great deal. And I don't like to watch them. I don't like the feeling around them. I don't like the sound, look, noise, smell. I don't like any of it. I only like individual type of physical activity. And I think that that harkens back to how much I dreaded gym class, how I came to hate all of that.

Elizabeth: I think that a survival mechanism for fat people around taunting and mocking and dieting, which I was always doing throughout grade school, is to separate yourself from your body to a degree because your body is never perceived as something that's okay. So in order for you to even mildly get a sense that you're okay, you need to distance yourself from it in some degree. So in terms of disembodiment, I feel like walking through the gym doors every single time was an exercise in disembodiment. Disembodiment would be the norm for me . . . because your body's on display and, so, I go somewhere else when that happens.

The public visibility of the body in physical education settings contributes to young women's alienation from physical education (Aldridge, 1998; Garrett, 2004) and is 
particularly difficult to negotiate for overweight girls (Cockburn \& Clarke, 2002). Moreover, girls monitor their own and each other's bodily appearance and size during physical education classes, which, according to Olafson (2002), plays a key role in their alienation from, and resistance to, physical education. Temperance, Elizabeth, and Starburst's heart-wrenching recollections about physical education illustrate how each of them experienced this surveillance and devaluing of their bodies.

Team games were a particularly tormenting part of physical education for several people we interviewed. For these fat students, team games seem like nothing more than "school-sanctioned bullying" (Azpiri, 2004, p. 1), which nurture fat phobia and size discrimination in quite obvious ways. A case in point is Jamie, who identified as Jewish, Scottish-Canadian, lesbian and sometimes bi, and who remembered baseball at grade school in terms of coercion, horror, concealment, and refusal:

Jamie: It was this horrible, horrible experience of being required to play a game I didn't want to play, and I was even worse, at that point, at hiding my feelings than I am now, and I'm still not very good at it, and it showed, big time. So, we were actually required to choose teams, you know like somehow people were chosen, so I was always the last chosen. You know, considering I didn't want to play, you'd think that I wouldn't care. Well, I cared! And, I would be sort of stuck in some outfield, and I would just sit there with some sourpuss on, and if a ball came over I'd sort of watch it, you know, fall to the ground, and it's like, this wasn't my idea. You're not getting me to do this.

Jamie recalled the emotional work she had to do when deprived of choice or input about whether and how she would take part in the game. Elizabeth talked about how she thought of herself as a "bad athlete" and experienced certain bodily movements or sports skills as awkward in physical education:

Elizabeth: Baseball was a high-pressure sport that really made me sweat because you had to stand in front of everybody, and I felt physically very awkward at sport. Swinging the bat, first of all, was awkward. Secondly, you put yourself out there more if you have a fat body. You've gotta run and your body jiggles, and you're not fast, and I wasn't agile. Volleyball was another one that made me cry. I remember being really bad at it, and the other kids being mad at me because I'd always miss the ball. I couldn't do whatever the motion, like, with the hands.

The social organization and visual economy of the game provoked great anxiety for Elizabeth. She felt awkward about swinging the baseball bat, about her agility, and running to the base "in front of everybody." Baseball puts the batter in a highly visible, isolated position. In a climate in which fat bodies are not accepted and appreciated, the fat-phobic gaze closes down possibilities for students with a "little roly-poly body" to have enjoyment, achievement, and success. Fat phobia in physical education is particularly damaging when the curricular activity, in this case the game of baseball, makes the students' body publicly visible. This is made worse when students are put on display in front of their peers and teachers (Cockburn \& Clarke, 2002), who treat those who are overweight with scorn and disdain (Jones et al., 2001). 
Within the "lean meritocracy" (Schwartz, 1986, p. 331) of physical education, fat bodies are ubiquitously constructed as not skilled, fit, or fast because, in visual terms, fatness is a representation of noncontrol. In the current historical moment, as Pronger (2002) explains, this is because fatness incites anxieties about the potential loss of motor and moral control and threatens the boundaries upholding a sovereign self. Overall, people interviewed for this project testified how difficult it was to contest these negative discourses about fatness. Most frequently, physical education practices foreclosed opportunities for students such as Temperance, Starburst, and Elizabeth to develop positive subject positions as fat students who could learn about motor control and human movement, develop their physical capabilities in encouraging and varied learning environments, and develop a positive, embodied subjectivity at school.

\section{Theme Number 2: Disciplining Fat Through Measurement}

Weighing and measuring students in physical education was one of the most explicit manifestations of fat phobia. Several people told extremely distressing narratives about being publicly weighed. These narratives reveal how weighing and measuring students - in the name of teaching health-related fitness or exercise science-disavows the psychic and social realities in which health and fatness are lived by students.

Physical education has been central to the development of techniques of weighing and measuring fatness that are, in turn, predicated on moral assumptions that bodily appearance mirrors the inner morality of the self (Jutel, 2005), and that the body, when weighed, tells a truth about the self (Schwartz, 1986). Starburst recalled how devastating it felt for her to be publicly weighed when she attended school in northern Ontario during the late 1950s.

Starburst: The most traumatic thing was that at the beginning of every year, they used to bring the scale in, and they would weigh everybody publicly. They would take your height and see what kind of physical shape you were in and what you'd done over the summer. That was like public humiliation, because I was always bigger than everybody, and not just bigger, but bigger and heavier by quite a margin. So it was tough. And if I knew when that day was coming, I would be sick and stay home from school. Then it wasn't quite as bad, because the next day, the teacher would catch you or something and say, "Oh, you have to come in and get weighed." So it would be just in front of her and not in front of the whole class. Because you know what it's like, particularly in the younger classes, people say things like, "Oh, you know, the scale's gonna break." All those kinds of comments that are really very hurtful.

Fifty years later Karyn, who identified as fat, straight, and White European, experienced similar public humiliation when being measured with skin calipers in her undergraduate physical education program.

Karyn: I thought I'd go into kinesiology. I started taking these classes, and they were horrible. They were like, oh my God, I still have nightmares about them. We were doing all these fitness testing. Do you know those fat pinchers?

Q: Calipers? 
Karyn: Yeah. Oh my God! In front of the class, get up and let's see how much fat is on your arm. I wanted to die! And all the super calculating we had to do. It was basically your body was the test subject, the test area. And I was of course in with all of these like ... jocks and like super cross country runners and everything that are really super athletic, and I was not super athletic, but I was good at gym. Like it was weird, right? The Prof. would put up all the like stats for the class, and so you could tell mine were pulling down all the averages in the class. [laughing] Oh my God, it was bad.

Karyn recalled how public weighing of students in physical education created anxiety about not only her own fat femininity but also "scrawny" and "big" masculinities:

Karyn: I remember in the senior level, we were being weighed that day. One guy who's a football player. He was a big guy, like, 360 pounds, and I remember this guy being teased. They started calling him "Circle."

Q: "Circle?"

Karyn: Like, 360 degrees. Don't talk about the women's weight, but the guy's weight can be joked about. Like, the guy is not going to be ashamed of his weight? But the poor guy, he must have been just horrified! I remember you could see in his face that this is not a cool thing, but he kind of rationalized it. He was a football player right? I guess there were some really scrawny guys that took the class that probably suffered. But at that point you're so focused, like I was so terrified. Don't weigh me in front of the whole class.

These supposedly educational moments are excruciating because the student's own body is being directly and publicly measured and weighed. As Karyn puts it, "It was basically your body that was the test subject, the test area." Brian Pronger (2002), in his book Body Fascism, explains how such fitness technologies in exercise science seek to calculate, as a means of fortifying, a centered, sovereign self. Here, the fat body "becomes the object that needs to be controlled through the technology of physical fitness in service of [the] subject" (p. 176). Endless refinement of weighing and measuring techniques, justified through supposedly nonideological, biomedical discourses of body composition and the body-mass index, strives to banish fatness from the "child." Yet these same disciplinary techniques also work to retain fatness through the ongoing biomedical investment in calculation, prevention, and measurement. In the Foucaultian sense, physical educators' attempts to eradicate or reduce obesity through weighing and weight reduction simultaneously work to incite and sustain an abject fascination with fatness. The experiences of our participants testify to the harmful and enduring effects these disciplinary techniques have on fat students' subjectivities in physical education.

Medical classificatory techniques have shifted from the overt associations between body size and shape and moral deviance in nineteenth-century anthropometry to the contemporary "aesthetics of health" in which outward appearance supposedly reflects one's well-being and commitment to self-improvement practices (Jutel, 2005). Starburt and Karyn's recollections illustrate how the context for such practices has shifted from the public weighing conducted in physical education classes in the 1950s to undergraduate exercise science classes in the twenty-first 
century. During the 1950s, according to Rafael Cervantes (2006), physical education in the U.S. responded to a national panic about physical fitness by framing physical fitness as necessary for citizenship. He argues that this articulation of the fit body to American citizenship is a crucial component in the emergence of the "obese child" as a public problem. Moreover, during the 1940s to 1960s, North American physical educators played an influential role in the social construction of the unhealthy, "obese child" by drawing upon gendered, racialized, and class-based tropes to categorize and measure ideal human body types, as Patricia Vertinsky (2002) explains:

Ancient physiognomic schemes and modern ones, such as Sheldon's somatotyping, bred normalcy into ways of seeing, evaluating and articulating the athletic potential of the body. ... . Once incorporated into the height and weight tables, charts and assessment techniques, professional entry requirements, fitness and training regimes, and physical education textbooks, such standards can produce what Foucault calls "normalizing effects," shaping how generations of individuals understand themselves, their bodies, and their athletic potential (pp. 114-115).

The pervasive cultural symbolism that associates the "obese child" with degeneration continues to be a central trope in the contemporary discourse about the "obesity epidemic" (Kirk, 2006).

\section{Theme Number 3: Sex and Gender Constructions in Fat Phobia}

The difficulties fat students experience in physical education are compounded for many people because fat subjectivities are, as Ahmed (2004) explains, constantly negotiated in terms of multiple racialized, classed, and sex/gender identities. This section illustrates how several students negotiated their gender and sex identities in relation to the symbolic associations between fatness and excess femininity, on the one hand, and athleticism and masculinity on the other. As mentioned earlier, fat women are positioned as too much woman and, given the association of athleticism with masculinity, they therefore cannot be athletic; the fat girl becomes synonymous with unathleticism. In contrast, men can have fat without being fat-yet when men are perceived to be fat, they risk being emasculated. While gay men cannot be or even have fat and remain sexually desirable, there is more leeway for queer women, especially those with female masculinities, to take up space as a fat person. Beyond the normative gender binary, the almost complete erasure of intersex subjectivity makes the negotiation of fatness even more fraught.

In her recollections of dodgeball, Sarah described how the fat body was gendered as female and designated as lazy:

Sarah: We weren't really encouraged and no accommodations were made to make it more accessible for everybody. There was no effort on the part of the teacher instead of playing dodge ball-where obviously the couple of "sporty guys" are going to pick off the "fat, lazy girls" - they wouldn't change it to make it better for all of us at all. They'd just leave it, whatever the curriculum was. So then in dodgeball you'd just get hit, and then you'd get to go and sit out. 
Fat phobia, in this instance, reinforced a gender binary and sexist hierarchy between "sporty boys" and "fat, lazy girls." Normative masculinity is linked with athleticism, whereas fatness is correlated with femininity and laziness. This enduring association between fatness and laziness is a gendered and racialized construction, underpinned by the need to contain and vilify threatening, polluting fluids of female reproductivity (Braziel, 2001; Kent, 2001; Shaw, 2005). Currently, Norman (2005) suggests that male youth who did not identify as fat in Ontario schools use the contemporary obesity discourse to construct and most usually to stabilize their own sense of embodiment as nonobese, White, masculine subjects.

Johnathon, who self-identifies as straight and overweight, recounted worrying about his body image when he was at school, particularly about his lack of muscular definition:

Johnathon: I didn't have muscular definition. I never thought of myself as having a good body. I guess I had weight issues, well, not really weight issues, but again, with the lack of definition with my stomach. My stomach was never very tight, defined.

He recalled having fat on particular parts of his body, which he describes as being "not defined" rather than subscribing to the identity category fat. Johnathon went on to articulate the gendered nature of fatness we describe above, in that, given fat's association with femininity, "real" (read heterosexual and masculine) men can have fat without being fat, whereas women cannot (Bordo, 1993).

Johnathon: For men, men can have certain amounts of baggage in a kind of simplistic sense and not be viewed as being fat or whatever.

Within mainstream gay male culture, however, it is generally more difficult for gay men to have fat in the same way. ${ }^{7}$ Gay men, such as Jean-Paul, are confronted with a far more limited range of acceptable and desirable body sizes because of the cult of male beauty arising from the aestheticization of fit male bodies in consumer and gay cultures (Monaghan, 2005). Here Jean-Paul describes the "fascist body standards of Church Street," which is in the center of Toronto's gay men's community:

I think there is, increasingly, a defined body type that is very muscular and lean. It requires one to spend a great deal of time working at the gym, eating properly, and taking steroids if necessary. In this pursuit of the perfect body, if you don't fit into this category, then you're not sexually desirable. If you're older, then it's even worse because then you become invisible, as well, and excluded from the sexual marketplace, as well as social activities, clubs, and bars.

Fat bodies may be slightly more accepted within queer women's communities, especially when associated with butchness and female masculinity. Sammy-Jo, who identifies as a queer dyke, feels she has more latitude to be overweight as a queer woman than when she identified as a straight woman: "I feel there is more room as a queer woman to fit a little outside the norm with my body." Similarly, Karen, who described herself as queer with a "complicated" gender identity, recalled being fearful as a result of being teased by boys at school: 


\section{Q: And did that fear come from your body issues around fat?}

Karen: [Pause]. When I was a kid, that was what I was aware of. In retrospect, I can also attribute some gender stuff to that, too. I wasn't really aware of that at the time.

As an adult, she talked about negotiating her fat embodiment in relation to being butch:

Karen: Now, exploring more of my butchness, my stereotypical masculine traits have helped me become more comfortable with my size because guys are allowed to take up space, right, but women are not supposed to.

Thus, for Karen, her increasingly butch gender identity redefines the amount of space she feels comfortable occupying. It might well be the case that female masculinity (Halberstam, 1997) makes fat female subjectivity slightly more livable or tolerable because butches and masculine women can "take up more space." This most likely occurs where there has been a history of fat activism in queer communities (LeBesco, 2001). Lee Monaghan (2005) suggests that the different levels of fat acceptance in gay men's gym culture and queer women's culture might be connected to gay male responses to HIV-AIDS and third-wave feminist body politics, respectively.

The claim, however, that female fatness is more easily constructed in conjunction with female masculinity or queerness in physical education settings needs to be cautiously examined in relation to the intense transphobia and homophobia of those contexts. Clearly, Karen wasn't able to openly embrace her masculinity while she was at school.

In terms of how intersexed people negotiate fat subjectivities, Scout was faced at school with the complete absence of any knowledge about being intersexed, which produced rather indefinable difficulties "negotiating her space." Scout, who has been "thin" and "overweight" at different periods in her life, described changes in her body size in multifaceted relations to her racial identity as "poor, White trash" and growing up not knowing she ${ }^{8}$ was intersexed. Scout's primary memory of physical education was the pressure to conform to a type of thin, White body constructed as desirable and skillful in physical education, especially in gymnastics.

Q: Would you say physical education has influenced how you feel about your body?

Scout: Dramatically ... dramatically. I grew up in Compton, California, and when we moved out of the Black neighborhood into a White neighborhood, all of these things shaped a perspective of what bodies should look like-what desirable bodies should look like. They should be White, and they should be blonde, and they should have blue eyes, and they should have tits out to here, and a heart shaped ass, and you know legs that go on for miles. It [physical education] was formative because it was the precursor to regimen and denial. So, yeah, it played a major role but in a disciplinary way.

Scout described changing ideals for the female body as she moved from a "Black" into a "White" neighborhood and how physical education reinforced "what 
desirable bodies should look like." Achieving one's ideal image produces immense pleasure (Silverman, 1995); however, fat bodies rarely, if ever, approximate the idealized body, and intersex bodies are simply beyond representation in physical education. Scout recalled "growing up without knowing she was an intersexed girl" and was deeply frustrated by the lack of knowledge or recognition about being intersexed "because there was no mirror for me. No role model for me to emulate." Being involved in gymnastics, Scout was also dealing with the "rigid strictness" about body composition in gymnastics where "

if you have the most miniscule amount of body fat, you need to get rid of that and the fatty fatty, and weigh, like, 87 pounds. ... So I just went off the scale. Like, at 16, I just totally quit gymnastics. My body hurt all the time. I was skin and bones. I felt awful, and I just went completely the opposite direction and just started eating. . . . I just started eating and eating and eating, you know. Like, five or ten pounds a year over my lifetime. . . Like, I'm 42, I have serious arthritis [laughs] and it's crazy.

This narrative only provides a very partial sense of how Scout articulated the complexity of changes in her body size, from thin when she was involved in gymnastics to later becoming fat, in relation to being intersexed. Nevertheless, her recollections point to the many registers in which students experience their body size and shape in physical education, which, as a profession, persistently fails to acknowledge or nurture such queer bodies. ${ }^{9}$

Both Scout and Karen talked about how their bodies occupied space in relation to their marginalized sex and gender identities. Being intersex was unintelligible within Scout's school context; she said, "it was really hard to negotiate my space" as a student. Being butch at school was transgressive and risky for Karen, who, by "exploring more of my butchness," has become more comfortable taking up space with her size as an adult. Thus, even as the underlying associations between fatness and femininity construct more potential to be fat and butch rather than gay and fat, intersex and gender-minority students such as Scout and Karen face particular challenges when negotiating their fat subjectivities at school.

\section{Theme \#4: Contesting Fat Phobia in Physical Education}

Negative perceptions of fat construct young women as "unfit," and in a study of 81 diverse women within a Canadian urban context, Carla Rice (2007) documents how such antifat messages compromise their physical abilities and identity choices. Although dominant discourses about fat as unhealthy and unfit permeated our participants' experiences of physical education, our participants nevertheless found room to resist and thereby resignify (Butler, 1993, 1997) such articulations of fat. This resistance took a number of forms. Some participants found ways to avoid physical education. Jamie, for example, "did not, want to be organized into playing anything, thank you very much," wanting rather to "find a shady tree and read [her] book." Similarly, Starburst, when asked by the interviewer what she learned from physical education, answered succinctly, "How to avoid it." On the other hand, some participants resisted fat-phobic representations of their bodies as unhealthy and unfit by not only participating in some activities but by excelling in them. Sarah, for example, talked about excelling on the flexibility and sit-up portions 
of the Canada Fitness Test, even as she failed and scored low on such exercises as the "endurance run," chin-ups, and push-ups. Karen, too, rejected the assumptions people made about her athletic ability on the basis of their visual association with fatness and lack of athleticism. Describing herself as a former competitive shotputter, Karen stated in our interview:

Karen: [Because of] the messages I was getting from my parents or doctors and, at school, from my peers or my teachers, I felt that my inability to do certain things or perform at a certain level physically was because of my body, because I was fat. People would look at me and just automatically assume, "Well, she can't do this, or she can't do that." Sometimes it was true, but not necessarily.

Although participants often rearticulated their bodies as strong or flexible, Sammy-Jo resisted fat phobia by insisting that her body was traditionally fit and could perform activities generally synonymous with small, lithe bodies.

Sammy-Jo: I felt big back then, and I always felt like I wasn't expected to be as good as the rest of the team, and you can play outfield because you're not expected to run as much and tag as much. The expectation was that I couldn't do as much, right? When I was in Grade 8, it actually surprised a lot of people. I used to run track in Grade 8. I used to run the 1500. I know people didn't think that I'd be able to do it, but I made it to the finals in this big competition. Even then I always felt like people thought, "What are you doing? Because you're so overweight, like, we don't have these expectations of you. You're not expected to be physically fit."

Often, resistance to fat phobia surfaced in later life for participants. Sarah, for example, when asked what sort of physical activities she engages in now, answered:

Sarah: I remember being younger, the girls who were interested in gym and track \& field - a lot of it was not about physical or mental abilities, it was just to get skinny. Really, to try and fit into this ideal: "Well I need to run so far or do these great things just to get skinny." As opposed to just enjoying sports and teams and the idea of being outside or anything. Part of the association with sport has to do with this kind of attitude of girls wanting to be skinny, which makes me just hate it even more. ... Whereas now, me doing stuff for me has nothing to do with that. It has to do with wanting to be outside, or wanting to go for a run, or wanting to feel healthy, or more awake, or more alert and more in control of your body. So I think my relationship to being physically active is very different.

Similarly, Elizabeth now has an athletic identity as "runner," and it continues to be important for her to separate her athleticism (being a runner) from her identifications with fatness and weight:

Elizabeth: I've lost a lot of weight in the course of being a runner. I don't really like to talk about weight loss because I always try dissociate myself from trying to do anything to do with my fatness. 
Celeste emphasized how she enjoyed and used her strength in field hockey:

Celeste: I always liked the fact that I was strong. So come high school, there were things I went into that could emphasize this strength. I played field hockey. So I was the last defenseman before the goalie. It was kind of fun because almost every game, I had broken shin pads because the girls, they see the goal, but I wouldn't let them through again, using my strength.

Celeste's narrative indicates how playing the position of sweeper, as she put it: "the last defenseman," is a specific space where the fat-yet-strong female body has value within the otherwise "lean meritocracy" (Schwartz, 1986, p. 331) of women's field hockey.

Celeste resisted the harmful effects of pervasive fat phobia by asserting her body's strength - contesting the symbolic conflation of fatness with the unathletic body. In a similar way, Moe used his powerful striking ability in baseball to reject anti-Semitic stereotypes of the Jewish male body as weak. Moe made a distinction between himself as being generally "not athletic" but still a "good hitter." In the except below, he described himself as not that "fast" or "skillful" but "a pretty strong kid":

Moe: I wasn't the slowest or the least athletic person in the class, but I was down there. I was in the bottom half or the bottom quarter. Some athletic pursuits, I could do some better than others. I was a pretty strong kid. The one thing I could do in baseball-I was a good hitter for some reason. But I wasn't a particularly fast runner or skillful thrower or anything like that.

Strength was one aspect of Moe's athletic embodiment that he remembered in positive terms, strength that translated into being a good hitter in baseball. Moe's interpretations about his hitting ability in baseball and his weight gain more generally, which he connected to his Jewishness and his parents' internment and immigration to the United States, resonate with one of Sander Gilman's (2004) cultural observations about the Jewish body in baseball. In Fat Boys Gilman suggests that "what looks like a healthy American body only obscures the Jew within" (p. 212) to the extent that, for the fat Jewish boy, identification with this quintessentially American sporting imaginary is all but unobtainable:

Tension between the struggle to free oneself from stigma and heavy identification with the stigmatized became a leitmotif of the transformation of the Jewish body in the 1980s. Physical transformation into a baseball player is shown to be form of false or at best superficial acculturation. (Gilman, 2004, p. 212)

Gilman attributes the unobtainable identification as a baseball player to antiSemitic constructions of the Jewish body as both "fat" and "weak." These identifications are also potentially feminizing because fat, as a result of the association with feminine abjectivity, on a man is emasculating. Yet, despite the freight of diasporic stereotypes about Jewish nonathleticism, Moe recalls his identification as a "good hitter" in grade school physical education. Although it is hard to say how Moe now thinks about his negotiation of his baseball athleticism in direct relation to his Jewishness, his narrative does support the more general notion that, within 
baseball specifically, fatness is worth something when imagined as "strong fat" propelling a gargantuan hitter.

\section{Theme Number 5: Fat-Positive Adult Fitness Spaces}

Two women talked about changes in their own perspectives about fatness as a result of being influenced by, or involved in, fat-activist politics. Indeed, the main reason we decided to interview adults rather than current students was to find out how people's experiences with fatness and physical activity changed after leaving school. We include these narratives to indicate the type of fat-positive discourses and politics that urgently need to be incorporated into physical education to counter the prevailing fat-phobic discourses of healthism and obesity.

Sarah and Temperance, both of whom identify as queer, talked about how they had managed to have some fat-positive experiences in a few adult fitness spaces, such as an aerobics class and a fitness gym. It is, unfortunately, crucial to point out that neither Sarah nor Temperance talked about having similar types of positive experiences during school physical education; these narratives, however, might help counter the pervasiveness of fat phobia in Canadian school physical education by portraying how, given fat politics and activism, fatness can be positively valued and embraced in physical activity spaces (Monaghan, 2005).

Sarah's feelings about her physical capabilities and fitness as a fat adult have changed dramatically since physical education made Sarah feel like "a totally alienated child" who had no physical capabilities. She recalled how physical education left her

thinking you can't do it, or you're not athletic enough, or you're not skinny enough, you're not this, you're not that. Whereas now, the physical activities that I do are totally for myself and it's fun and it's great. It makes me feel good having a body, and having muscles, and being able to do things. Nobody's forcing you to do it, it's entirely optional, so you end up feeling really great about it.

Sarah explained how important it is has been to see positive representations of fat bodies involved in physical activity, such as her aerobics instructor:

For me it depended on who the instructor was. [laughing]. I remember for a long time when I was in Townville there was a little gym around the corner in our little neighborhood, and they had an afternoon aerobics class. One of the instructors there, she's quite a large woman and was obviously very, very fit. She had amazing lung capacity and was really muscular, but also just had a giant layer of fat on top of her muscles. It was very flabby fat. You know, those kinds of hard fat and flab fat?

Q: Yeah.

Sarah: She was very flab fat. And she'd wear a tank top and little shorts, so when she'd do aerobics, she'd just be shaking all over the place. And all . . .

Q: [laughing] That's awesome. 
Sarah: I know, I fucking loved it! She's loving just sweating, being active, and being fit.

Temperance proclaimed she would never "take gym" again after Grade 10 because of her traumatic experiences as a fat student. As an adult, Temperance recounted how she gradually began to exercise and associated this activity with "my body feeling really healthy." Temperance related being healthy and energetic with walking or working out at her gym:

Temperance: After Grade 10 you no longer had to take gym. God help me if I was ever going to take gym ever, ever, ever. And I never worked out ever. . . . I remember moving to Toronto and walking for exercise. I wore my headphones, and I'd have my Discman. I'd walk hours at a time simply because I had a really great CD on. All of the sudden my body started feeling really healthy, and my energy levels improved. I would do it to reduce stress rather than falling back on ... . um . . . the other less healthy stress mechanisms. I really really loved it. But, I don't know if I perceived it as exercise.

As an adult, Temperance actively rejected the medicalized logic that physical activity and, in part, being healthy are associated with losing weight. She explained how she started to form identifications with fat bodies as physically active and working out:

I started hearing about Curves, the gym chain, a few years ago. At the time I was partnered with a varsity rugby athlete, and she was also really big. So I felt like we could dialogue around the gray space between being allowed to be fat and also trying to not rebel against fat phobia and making healthy choices.

Temperance acknowledged her ambivalent identifications toward working out and losing weight that she described as "the gray space between being allowed to be fat."

So I felt like I could say to her, "I'm feeling complicated. I feel like I'd like to be active, but I don't want this to be about losing weight. Cause if I get into that frame of mind I'll obsess about diets, and I'll be happy about losing weight, and I don't want to get locked into that."

So I joined Curves. I went to my interview, and there's this plus-sized woman in this baby pink velour jumpsuit working at the front desk. Immediately, I'm sold. I said to her, "I'm an easy sell, but you cannot promote measuring me, weighing me, or weight loss. The minute you say any of those things, I'm gone." So, she said, "Okay." She didn't mention any of those things. And Curves was like ... Curves was a fucking party to me. . . The culture was very fat friendly. Lots of fat women worked there. Lots of fat women worked out there and remained fat. I loved seeing that. I began to interact with my body as an active fat body [our italics].

Hence, the fat-friendly culture of Curves provided a unique material and psychic space for Temperance to consolidate her identification with the fat body as active. Even though she came to realize that Curves is "owned by evangelical Christians" 
and is a "weight-loss outfit," two facts that lead Temperance to eventually discontinue her membership, Temperance's experiences at Curves helped her to formulate a particular fat politic that actively rejects and resignifies the logic of the obesity discourse that conflates the fat body with inactivity and being unhealthy.

Lynda Johnston (1996) suggests that gyms, as specific places of training, provide a "material and discursive environment that reworks bodies in the feminine/masculine binary" (p. 327). Whereas Johnston documents how the ripped muscularity of a female bodybuilder is constituted as abject within male gym spaces because it pollutes the stable boundaries of soft, weak, leaking feminine corporeality; the very presence of fatness, however gendered, in most gym spaces is constituted as abject. In her postcolonial analysis of movement, Jane Unan (2003) identified how the linear motions proscribed by North American fitness equipment symbolically serve to reproduce White normative subjects:

The civilized, rational, and linear movement that produce civilized and normative subjects and space, like the rational, coherent subject of gyms and the equipment therein, are in contrast to irrational, incoherent, "swerving" movements. (p. 90)

She goes on to insightfully propose that movement can be resistive when it challenges movement patterns, by "deviating from the (straight) line" (Unan, 2003, p. ii). One could argue, then, that the name "Curves" disrupts how fitness gyms symbolically produce not only masculinity but also Whiteness in the valorization of hard, tight bodies. We might then hope that the name "Curves" heralds the possibility of working out while keeping one's curves - that is, becoming fit while fat. Within a fat-positive imagination, this gym space markets the hope of fitness that, although still through the linear motion of fitness equipment, maintains the incoherent, curvy fatness of the body. However, when Temperance declared that she "didn't know they [Curves] were a weight-loss outfit" or "owned by evangelical Christians," it becomes clear that this fat-friendly space is forcefully normative in other ways and, in the end, like all diet and exercise regimes, still succumbs to a mantra and market of weight loss.

\section{In/conclusion}

For most people we interviewed, constructing a positive fat subjectivity in physical education spaces was usually foreclosed by fat-phobic attitudes and practices that affected them in profound and overwhelmingly negative ways. For some individuals, it was possible to temporarily negotiate a fat identity within physical education but only in very restricted, nonnormative ways. This involved confronting and resisting fat-phobic assumptions and practices through emotionally draining and intricate social, psychic, and kinesthetic maneuvers. These moments of fat survival and resistance by students within physical education spaces testify to the students' ethical responses in the face of contemporary unethical cultural and pedagogical investments in fat phobia. Being a fat kid in physical education is close to what Kelly Oliver (1998) describes as being a subject without subjectivity. It is important, then, to name the agency of our participants to negotiate and survive pervasive fat phobia in physical education. It is also important, however, to temper such discussions of 
agency with a pointed political recognition of the subjugation of fat people and the social structures like patriarchy, capitalism, and racism that facilitate and create that subjugation. Because we recognize the agency of our participants, we are not asserting that they acted free and clear of oppressive power dynamics. As Butler (1993) argues in Bodies That Matter, recalling Foucault's (1978) discussion of reverse and counter discourses in The History of Sexuality, expressions of agency are limited by the very dominant discourses and power relations that necessitate that agency. Butler states:

The paradox of subjectivation . . . is precisely that the subject who would resist such norms is itself enabled, if not produced, by such norms. Although this constitutive constraint does not foreclose the possibility of agency, it does locate agency as a reiterative or rearticulatory practice, immanent to power, and not a relation of external opposition to power. (p. 15)

Fat phobia is oppressive. Fat phobia contains and restrains fat people even as fat people formulate complicated resistances to it.

We asked participants to talk about the type of educational and structural changes that might alleviate fat phobia in physical education. Temperance recommended eliminating gym altogether because she "learned more about hating her body than making it healthy" through physical education at school. Along similar lines, Starburst expressed grave concerns about the potential for harm in trying to raise awareness about obesity given the current attempts to "purge the nation of fat kids":

You can be sure that every teacher in every class is trying to raise awareness around obesity. I think of all the little children sitting there wishing they could sink into their seats when it's being talked about. So whatever's done, I think it should be very carefully thought out and by people who really are super sensitive to the harm that can be done in trying to create something good.

Elizabeth felt that "there's still a long way to go to educate people to the idea that fat can be fit and not place this value on slenderness" and thought it was necessary to teach against fat bias in education. For Karyn, this means "challenging official views on fatness" because "speaking about fatness and being critical of definitions is really important and political." Karen felt that bringing fat activists such as Miss G, Fat Femme Mafia, or Pretty, Porky and Pissed Off into Toronto schools would help inform teachers and students. Anticipating resistance from parents, teachers, and school officials, Karen suggested it would be necessary to substantiate this type of fat activism in schools with backing from critical academic research and introducing Women's Studies programs into high schools.

Jamie was pessimistic about achieving any sort of change on progressive social issues within the educational system because of the lack of financial resources, privatization, and ineffectual left-wing politics in Canada. Other people were slightly more optimistic and suggested various changes in curriculum approaches, how students might critically engage with ideas about fatness, and the training of physical education teachers.

Based on our interviews with these people who experienced and struggled against fat phobia in physical education, we are calling for a change to educational 
structures that directly relates to the oppression of fat kids in physical education. The change we encourage goes beyond the attitudes of individual teachers or administrators; as we argue throughout the article, fat phobia is a society-wide problem. Curriculum changes and inclusive physical education pedagogies, however, - ones that would not only allow fat children to participate in physical education but would also directly validate and legitimize fat bodies-would go a long way in easing the trauma of fat children in physical education.

\section{Notes}

1. Abjection is part of the process of subject formation concerned with protecting the self from the threat posed to stable bodily boundaries by the feminine bodily fluids and leaks, substances coded as polluting and revolting (Kristeva, 1982). In contemporary culture, fat pervasively represents the abject. Although we refer to abjection only briefly in this article, we recognize it is central to positing contemporary theories of fat subjectivity (Braziel, 2001; Kent, 2001; Moon \& Sedgwick, 2001). In future work, we hope to complement our sociological interpretations with more detailed analysis of how abjecting fatness was integral to students' negotiations of fat phobia in physical education.

2. It is important to note that, while fat women are imaginatively "hyper-women," they are at the same time asexualized. Fat women are not sexy women and are forcibly excluded from the subjectivity of "woman" because they do not, ostensibly, maintain disciplinary regimes of diet and exercise that are implicit within the category "woman" (Bartky, 1997). As Braziel (2001) argues, however, fat women remain hyper-women inasmuch as they represent feminine excess. The fat woman is hyper-woman because she stands for an excess of female-ness that cannot "be" in a patriarchy. Existing on the "margins of representability" (Braziel, p. 233), fat women as hyper-women, in fact, define the patriarchal subject category of "women."

3. Thus, in contemporary discourses regarding obesity, the fat Black female is, once again, made "mammy" and placed in binary opposition to the iconoclastic "jezebel." Both representations position the Black woman as "animalistic," the mammy through her hyper-corporeality, the jezebel through her hyper-sexuality. See Hill Collins (1997) for a discussion of the mammy-jezebel binary and its on-going currency in representations of African American women.

4. We contend, along with Gilman (2006), that Bruch's theoretical and therapeutic approaches to fatness warrant detailed, historicized reinterpretation rather than Gard and Wright's (2005) unmitigated, ahistorical dismissal of her work on the grounds that it was scientific, antifeminist, and psychoanalytic per se: "In short, just like contemporary obesity science, Bruch's work was a cocktail of science, morality, and (in Bruch's case, Freudian) ideology" (Gard \& Wright, p. 74).

5. Temperance used the term bio-femme on her demographic form to describe her gender/sex. Although we cannot provide a definitive or generalized explanation of this term, we suggest Temperance was self-identifying her sex as biologically female (rather than transitioned or transsexual female) and her gender identity as a femme (as distinct from feminine gender identity and perhaps, but not necessarily, in relation to butch gender).

6. We are sensitive to the risks of reductionism and essentialism involved in using demographic descriptors to represent complex, shifting aspects of individual's subjectivities. We attempted to mitigate this limitation by using terms given to us by the individual.

7. Other gay men interviewed for the larger project also talked about fat phobia within many gay male communities, with the important exception of gay male "bear" subcultures (Monaghan, 2005; Suresha, 2002; Textor, 1999). We haven't included an analysis of their experiences in this article because they did not self-identify as fat or overweight. We anticipate analyzing how people 
who did not identify with a marginalized social group (such as undervalued body size/shape) experienced and negotiated oppressive discourses about embodiment, (e.g., how gay men negotiate fat-phobic discourses; how able-bodied people negotiate ableist discourse, etc.)

8. We are using the gender pronoun she because Scout self-referenced using the phrase intersexed girl during the interview.

9. We use the term queer bodies to refer not simply to nonnormative sexual and gender bodies or LGBT embodiments but, following Dana Seitler (2004) in Queer Physiognomies, to sexualand gender-variant bodies that are mutually produced by, and productive of, racial categories, dis/abilities, and "abnormal" and "freakish" physical appearance and anatomies. This is because queer categories are not discrete but produced through similar logics, such as visibility, degeneracy, atavism, and miscegenation (seeing is believing, fears about development, change and mixing).

\section{References}

Ahmed, S. (2004). Differences that matter: Feminist theory and postmodernism. Cambridge, UK: Cambridge University Press.

Aldridge, M. (1998). "On display and vulnerable": An investigation of the importance and significance of body image and self image for girls in Physical Education. MA(Ed) Thesis, University of Southampton, UK.

Argell, S. (2005, April 7). Toronto slimmest city next to Vancouver: Saskatoon, Halifax most obese: Study. The National Post, pp. A1, A24.

Anzieu, D. (1989). The skin ego. New Haven, CT: Yale University Press.

Armour, K. (1999). The case for a body-focus in education and physical education. Sport Education and Society, 4(1), 5-16.

Azpiri, J. (2004). The attack of the red rubber ball. Retrieved November 30, 2006, from http://thetyee.ca/Sports/2004/07/05/The_Attack_of_the_Red_Rubber_Ball/.

Bartky, S.L. (1997). Foucault, femininity, and the modernization of patriarchal power. In D. Meyers (Ed.) Feminist social thought: A reader, (pp. 93-111). New York: Routledge.

Benhabib, S. (1992) Situating the self: Gender, community and postmodernism in contemporary ethics. Cambridge, UK: Polity.

Bordo, S. (1993). Unbearable weight: Feminism, Western culture, and the body. Berkeley: University of California Press.

Brabazon, T. (2006). Fitness is a feminist issue. Australian Feminist Studies, 21(49), $65-83$.

Braziel, J.E. (2001). Sex and fat chicks: Deterritorializing the fat female body. In K. LeBresco J. E. Braziel. (Eds.), Bodies out of bounds: Fatness and transgression, (pp. 231-254). Berkley: University of California Press.

Braziel, J.E., \& LeBesco, K. (2001). Bodies out of bounds: Fatness and transgression. Berkley: University of California Press.

Burns, R. (1998). Dis/ease: Discourses in Australian health and physical education. In A. Mackinnon, A. Prentice, \& I. Elgqvist-Saltzman (Eds.), Education for women in the 21st century: Dangerous terrain for women, (pp. 66-80). New York: Routledge.

Butler, J. (1992) Gender trouble: Feminism and the subversion of identity. New York: Routledge.

Butler, J. (1993). Bodies that matter: On the discursive limits of "sex." New York: Routledge.

Butler, J. (1997). The psychic life of power. Stanford, CA: Stanford University Press.

Callard, F. (1998). The body in theory. Society and Space, 16(4), 387-400.

Cervantes, R. (2006). Unfit for citizenship: Fitness, ambiguity and the problem of the physically (in)active child. $\mathrm{PhD}$ Thesis, Communication Studies, University of Iowa, Iowa City, IA. 
Cockburn, C., \& Clarke, G. (2002). "Everybody’s looking at you!": Girls negotiating the "femininity deficit" they incur in physical education. Women's Studies International Forum, 25(6), 651-661.

Colls, R. (2002). Review of 'Bodies out of bounds: fatness and transgression'. Gender, Place and Culture: A Journal of Feminist Geography, 9, 218-20.

Colls, R. (2007). Materialising bodily matter: Intra-action and the embodiment of "Fat." Geoforum, 38(2), 353-365.

Colquhoun, D. (1990). Images of healthism in Health-Based Physical Education. In D. Kirk \& R. Tinning (Eds.), Physical education, curriculum and culture: Critical issues in the contemporary crisis, (pp. 225-251). Philadelphia, PA: Falmer Press.

Cooke, K. (1996). Real gorgeous: The truth about body and beauty. New York: W.W. Norton.

Crawford, R. (1980). Healthism and the medicalization of everyday life. International Journal of Health Services, 7, 663-680.

Diprose, R. (2002). Corporeal generosity: On giving with Nietzsche, Merleau-Ponty, and Levinas. Albany: State University of New York.

Duncan, N. (1996). Bodyspace: Destabilizing geographies of gender and sexuality. London, UK: Routledge.

Evans, J., Evans, B., \& Rich, E. (2003). "The only problem is, children will like their chips": Education and the discursive production of ill-health. Pedagogy, Culture \& Society, 11(2), 215-240.

Evans, J., Evans, R., Evans, C., \& Evans, J. (2002). Fat-free schooling: The discursive production of ill-health. International Studies in Sociology of Education, 12, 191-215.

Evenson, B. (2002a, November 5). "I'm a good example." The National Post, pp. AL1, AL6.

Evenson, B. (2002b, November 7). Don't blame the kids. The National Post, pp. AL1, AL6.

Evenson, B. (2002c, November 8). The thin gene. The National Post, p. A19.

Fern, E.F. (1982). The use of focus groups for idea generation: the effects of group size, acquaintanceship, and moderator on response quantity and quality. JMR, Journal of Marketing Research, 19, 1-13.

Fraser, N., \& Nicholson, L.J. (1990). Social criticism without philosophy: An encounter between feminism and postmodernism. In L.J. Nicholson (Ed.), Feminism/postmodernism, (pp. 19-38). New York: Routledge.

Freespirit, J., \& Alderbaran. (1983). Writings from the fat underground: Fat liberation manifesto. In L. Schoenfielder \& B. Wieser (Eds.), Shadow on a tightrope: Writings by women on fat oppression (pp. 52-53). San Francisco: Aunt Lute.

Foucault, M. (1978). The history of sexuality, Volume I: An introduction. (R. Hurley, Trans.). New York: Vintage.

Fuss, D. (1995). Identification papers. New York: Routledge.

Gard, M., \& Wright, J. (2001). Managing uncertainty: Obesity discourse and physical education in a risk society. Studies in Philosophy and Education, 20, 535-549.

Gard, M., \& Wright, J. (2005). The obesity epidemic: Science, morality and ideology. New York: Routledge.

Garrett, R. (2004). Negotiating a physical identity: Girls, bodies and physical education. Sport Education and Society, 9(2), 223-237.

Gatens, M. (1996). Imaginary bodies: Ethics, power and corporeality. New York: Routledge.

Gilman, S.L. (2004). Fat boys: A slim book. Lincoln, NE: University of Nebraska Press.

Gilman, S.L. (2006). Obesity, the Jews and psychoanalysis: On shaping the category of obesity. History of Psychiatry, 17(1), 55-66.

Grosz, E. (1994). Volatile bodies: Toward a corporeal feminism. Bloomington: Indiana University Press. 
Grosz, E. (1995). Space, time and perversion. New York: Routledge.

Halberstam, J. (1997). Female masculinities. London: Duke.

Health Canada. (2002). Chapter 5: Primary health care and prevention. In Building on values: The future of health care in Canada, (pp. 115-136). Accessed at: http//www. hsc.gc.ca/english/pdf/romanow/pdfs/HCC_Chapter_5.pdf

Herndon, A. (2002). Disparate but disabled: Fat embodiment and disability studies. NSWA Journal, 14(3), 120-137.

Hill Collins, P. (1997). Pornography and Black women's bodies. In Gender violence: Interdisciplinary perspectives (pp. 395-399). New York: New York University Press.

Hubbard, V. (1983). Summer. In L. Schoenfielder \& B. Wieser (Eds.), Shadow on a tightrope: Writings by women on fat oppression (pp. 99-101). San Francisco: Aunt Lute.

Huff, J.L. (2001). A "horror of corpulence": Interrogating Bantingism and mid-nineteenth century fat-phobia. In J.E. Braziel \& K. LeBesco (Eds.), Bodies out of bounds: Fatness and transgression (pp. 19-38). Berkeley: University of California Press.

International Sociological Association. (2002). Programme information. Retrieved from the World Wide Web on 03/09/02 (http://www.ucm.es/info/isa/tg03.htm).

Jacobs, J.L. (2004). Women genocide and memory: The ethics of feminist ethnography in Holocaust research. Gender \& Society, 18(2), 223-238.

Johnston, L. (1996). Flexing femininity: Female body-building refiguring "the body." Gender, Place and Culture, 3(2), 327-340.

Johnston, L. (1998). Reading the sexed body and spaces of the gym. In H. Nast \& S. Pile (Eds.), Places through the body (pp. 244-262). London: Routledge.

Jones, J., Bennett, S., Olmsted, M., Lawson, M., \& Rodin, G. (2001). Disordered eating attitudes and behaviors in teenaged girls: A school-based study. Canadian Medical Association Journal, 165(5), 547-552.

Jutel, A. (2005). Weighing health: The moral burden of obesity. Social Semiotics, 15(2), $113-125$.

Kent, L. (2001). Fighting abjection: Representing fat women. In J.E. Braziel \& K. LeBesco (Eds.), Bodies out of bounds: Fatness and transgression (pp. 130-150). Berkley: University of California Press.

Kennedy, M. (2005, July 7). Fat nation. The National Post, pp. A1, A4.

Kirk, D. (2006). The "obesity crisis" and school physical education. Sport Education and Society, 11(2), 121-133.

Kirk, D., \& Colquhoun, D. (1989). Healthism and physical education. British Journal of Sociology of Education, 10(4), 417-434.

Kirkey, S. (2002, November 6). For a child, how big is too big? Early dieting can lead to neuroses. The National Post, pp. AL1, AL6.

Kristeva, J. (1982). Powers of horror: An essay on abjection [Trans. L.S. Roudiez]. New York: Columbia University Press.

Kvale, S. (1995). InterViews: An introduction to qualitative research interviewing. Thousand Oaks, CA: Sage.

LeBesco, K. (2001). Queering fat bodies/politics. In J.E. Braziel \& K. LeBesco (Eds.), Bodies out of bounds: Fatness and transgression, (pp. 74-87). Berkley: University of California Press.

Longhurst, R. (2001). Bodies: Exploring fluid boundaries. London, UK: Routledge.

Longhurst, R. (2005). Fat bodies: Developing geographical research agendas. Progress in Human Geography, 29(3), 247-259.

Lyons, P. (1989). Fitness, feminism, and the health of fat women. Women and therapy: A feminist quarterly, 8(3), 65-77.

Macdonald, D., Kirk, D., Metzler, M., Nilges, L., Schempp, P., \& Wright, J. (2002). It's all very well in theory: Theoretical perspectives and their applications in contemporary pedagogical research. Quest, 54(2), 133-156.

Malson, H. (1998). The thin woman: Feminism, post-structuralism and the social psychology of anorexia nervosa. New York: Routledge. 
Marvin, S., \& Medd, W. (2004). Metabolisms of obesity: Fat across bodies, cities and sewers. Paper for the Urban Vulnerability and Network Failure Conference, SURF. Manchester, U.K., April 29-30.

Mayer, V.F. (1983). Foreword. In L. Schoenfielder \& B. Wieser (Eds.), Shadow on a tightrope: Writings by women on fat oppression (pp. 3-14). San Francisco: Aunt Lute.

McRuer, R. (2006). Crip Theory. New York: New York University Press.

Mishler, E. (1991). Representing discourse: The rhetoric of transcription. Journal of Narrative and Life History, 1(4), 255-280.

Mishler, E. (1995). Models of narrative analysis: A typology. Journal of Narrative and Life History, 5(2), 87-123.

Monaghan, L. (2005). Big handsome men, bears and others: Virtual constructions of "fat male embodiment." Body \& Society, 11(2), 81-111.

Moon, M., \& Sedgwick, E.K. (2001). Divinity: A dossier, a performance piece, a littleunderstood emotion. In J.E. Braziel \& K. LeBesco (Eds.), Bodies out of bounds: Fatness and transgression (pp. 292-328). Berkley: University of California Press.

Moore, O. (2005, April 21). Canada's children ranked among world's fattest. The Globe and Mail, p. A6.

Mosher, J. (2001). Setting free the bears: Refiguring fat men on television. In J.E. Braziel \& K. LeBesco (Eds.), Bodies out of bounds: Fatness and transgression (pp. 166-195). Berkley: University of California Press.

Morimoto, L. (2006). Teaching as transgression: An Autoethnography of a fat PE instructor. Paper presented at the North American Society for Sociology of Sport. Vancouver, BC. Nov 1-4.

Morris, M., \& Weaver, J. (2002). Difficult memories: Talk in a (post) holocaust era. New York: Peter Lang.

Moss, P., \& Dyck, I. (2002). Women, body, illness: Space and identity in everyday lives of women with chronic illness. Oxford, UK: Rowman \& Littlefield.

Mouffe, C. (1997). Feminism, citizenship and radical democratic practice. In D. Meyers (Ed.), Feminist social thought: A reader (pp. 533-44). New York: Routledge.

Norman, M. (2005). Bodies unbound: Obesity discourses and the policing of young people's bodily boundaries. Paper presented at the North American Society for Sociology of Sport. Winston-Salem, NC. Oct 26-29.

Norman, S.J. (1983). Rec center. In L. Schoenfielder \& B. Wieser (Eds.), Shadow on a tightrope: Writings by women on fat oppression (pp. 97-98). San Francisco: Aunt Lute.

Ogilvie, M. (2006, January 27). Can a city make you fat? The Toronto Star, pp. D1, D6.

Olafson, L. (2002). "I hate Phys. Ed.": Adolescent girls talk about physical education. The Physical Educator, 52(2), 67-74.

Oliver, K. (1998). Subjectivity without subjects: From abject fathers to desiring mothers. Lanham, MD: Rowman \& Littlefield.

Ontario Ministry of Education. (2005). Policy/Program Memorandum No. 138: Daily Physical Activity in Elementary Schools, Grades 1-8. Accessed on March 1, 2007, at http://www.edu.gov.on.ca/extra/eng/ppm/138.html

Parks and Recreation Ontario. (2007). Children's Fitness Tax Credit. Accessed on March 1, 2007, at http://www.prontario.org/creditFAQ.htm

Pronger, B. (2002). Body fascism: Salvation in the technology of physical fitness. Toronto: University of Toronto Press.

Prosser, J. (1998). Second skins: The body narratives of transsexuality. New York: Columbia University Press.

Rice, C. (2006 [1994]). Out from under occupation: Transforming our relationships with our bodies. In A. Medavoraski \& B. Cranney (Eds.), Canadian woman studies: An introductory reader (2nd ed.) (pp. 411-423). Toronto: Inanna Publications \& Education.

Rice, C. (2007). Becoming the fat girl: Acquisition of an unfit identity. Women's Studies International Forum, 30(2), 158-174. 
Rice, C., \& Russell, V. (2002). Embodying equity: Body image as an equity issue. Toronto: Green Dragon Press.

Rich, E. (2003). Exploring constructions of the body, (ill)health and identity in schools: The case of anorexia nervosa. Paper presented at the 2nd Global Conference: Making Sense of Health, Illness and Disease. Oxford, UK, July 14-17.

Shaw, A. (2005). The other side of the looking glass: The marginalization of fatness and Blackness in the construction of gender identity. Social Semiotics, 15(2), 143-152.

Schilder, P. (1978) The image and appearance of the human body: Studies in the constructive energies of the psyche. New York: International Universities Press.

Schildrick, M. (2002). Embodying the monster: Encounters with the vulnerable self. Thousand Oaks, CA: Sage.

Schoenfielder, L., \& Wieser, B. (1983). Shadow on a tightrope: Writings by women on fat oppression. San Francisco: Aunt Lute.

Seitler, D. (2004). Queer physiognomies: Or, how many ways can we do the history of sexuality? Criticism, 46(1), 71-102.

Scott, J.W. (1992). "Experience.” In J. Butler and J.W. Scott (Eds.), Feminists theorize the political (pp. 22-40). New York: Routledge.

Schwartz, H. (1986). Never satisfied: A cultural history of diets, fantasies and fat. New York: Free Press.

Silverman, K. (1995). On the threshold of the visible world. New York: Routledge.

Stearns, P. (2002). Fat history: Bodies and beauty in the modern west. New York: New York University Press.

Sullivan, N. (2003). A critical introduction to queer theory. New York University Press.

Suresha, R. (2002). Bears on bears: Interviews and discussions. Los Angeles: Alyson Press.

Textor, A. (1999). Organization, specialization and desires in the Big Men's Movement: Preliminary research in the study of subculture-formation. International Journal of Sexuality and Gender Studies, 4(3), 217-239.

Tinning, R. (1985). Physical education and the cult of slenderness. ACPHER National Journal, 107, 10-13.

Tinning, R., \& Glasby, T. (2002). Pedagogical work and the "Cult of the Body": Considering the role of HPE in the context of the "New Public Health." Sport Education and Society, 7(2), 109-119.

Unan, J. (2003). Colonizing movement: Exercise and the (re)production of Whiteness. MSc Thesis. Dept. of Community Health, University of Toronto. Toronto, Ontario.

Vertinsky, P. (2002). Embodying normalcy: Anthropometry and the long arm of William H. Sheldon's somatotyping project. Journal of Sport History, 29(1), 95-133.

Wharf Higgins, J., Gaul, C., Gibbons, S., \& Van Gyn, G. (2003). Factors influencing physical activity levels among Canadian youth. Canadian Journal of Public Health, 94(1), $45-51$.

Weedon, C. (1997). Feminist practice and poststructuralist theory (2nd ed). Oxford: Blackwell.

Weiss, G. (1999). Body images: Embodiment as intercorporeality. New York: Routledge. 